\title{
PENGARUH BIMBINGAN KELOMPOK DALAM MENINGKATKAN KEMAMPUAN MENGELOLA EMOSI SISWA KELAS XI DI SMA N 8 KOTA BENGKULU
}

\author{
Shella Purnama, Wayan Dharmayana, Rita Sinthia \\ Program Studi Bimbingan dan Konseling Fakultas Keguruan dan Ilmu Pendidikan \\ Universitas Bengkulu \\ Shellapurnama799@yahoo.co.id,dharmayana@unib.ac.id, ritasinthia@unib.ac.id
}

\begin{abstract}
ABSTRAK
Tujuan penelitian ini adalah untuk mendeskripsikan pengaruh layanan bimbingan kelompokterhadap peningkatan kemampuan mengelola emosi siswa kelas XI SMA Negeri 8 Kota Bengkulu. Teknik pengumpulan data dalam penelitian ini menggunakan skala sikap. Teknik pengambilan sampel menggunakan purposive sampling. Sampel dalam penelitian ini adalah siswa kelas XI IPA1 yang memiliki tingkat kemampuan mengelola emosi rendah. Hasil dari penelitian ini menunjukkan adanya pengaruh yang signifikan layanan bimbingan kelompok terhadap peningkatan kemampuan mengelola emosi pada siswa. Hal ini dapat terlihat dari hasil pengujian hipotesis diperoleh nilai $\mathrm{Z}=-2.879(\mathrm{p}<0,05)$ maka $\mathrm{H}_{0}$ ditolak. Dapat disimpulkan, terdapat pengaruh yang signifikan layanan bimbingan kelompok terhadap peningkatan kemampuan mengelola emosi siswa kelas XI SMA Negeri 8 Kota Bengkulu.
\end{abstract}

Kata kunci: bimbingan kelompok, kemampuan mengelola emosi

\section{THE INFLUENCEOF GROUP GUIDANCE IN IMPROVING STUDENTS MANAGING EMOTIONS ABILITY AT CLASS XI OF SMA N 8 BENGKULU}

\begin{abstract}
The purpose of this study was to determine the influenceof group guidanceto improved managing emotions ability in class XI students of SMA Negeri 8 Kota Bengkulu. Data collection techniques in this study using theattitude scale. The sampling technique using purposive sampling. The sample in this study is class XI IPA 1 who have low managing emotions ability levels. The results of this study indicate a significant influence of group guidanceservices improved managing emotions abilitystudents. It can be seen from the results of hypothesis testing result value $\mathrm{Z}=-2.879(\mathrm{p}<0,05)$ then $\mathrm{H}_{0}$ rejected. It can be concluded, there is a significant influence of group guidanceservices improved students managing emotions ability in class XI SMA Negeri 8 Kota Bengkulu.
\end{abstract}

Keywords: Group Guidance,Managing Emotions Ability 


\section{Pendahuluan}

Masa remaja adalah masa peralihan antara masa anak-anak ke masa dewasa. Pada masa ini, remaja mengalami perkembangan mencapai kematangan fisik, mental, sosial, dan emosional. Batasan masa remaja awal berlangsung umur 13 tahun sampai umur 18 tahun yaitu usia matang secara hukum. Masa remaja ini memiliki energi yang besar, emosinya berkobar-kobar, sedangkan pengendalian dirinya belum sempurna (Ali \& Asrori, 2004: 67).

Secara tradisional masa remaja dianggap sebagai periode "badai dan tekanan" suatu masa dimana ketegangan emosi yang tinggi akibat perubahan fisik dan kelenjar.Sebagian besar remaja mengalami ketidakstabilan dari waktu ke waktu sebagai konsekuensi usaha penyesuaian diri terhadap pola perilaku baru (Hurlock,2003: 212). Pengelolaan emosi pada remaja sangat dibutuhkan agar remaja dapat mencapai kematangan emosi yang optimal. Pada kenyataannya, masih sering terjadi peristiwa pada remaja tidak dapat mengelola emosinya. Goleman (1996: 58) mengemukakan bahwa kemampuan mengelola emosi adalah kemampuan melepaskan suasana hati yang tidak mengenakkan. Menangani perasaan agar terungkap dengan tepat dan selaras, sehingga tercapai keseimbangan dalam diri individu.

Riaty (2015: 130)berpendapat bahwa siswa cenderung bersikap emosional karena tidak mampu mengelola dorongan hatinya dan bertahan terhadap frustasi yang dirasakannya, sehingga pada saat siswa merasa marah atau kesal, siswa tidak mampu berpikir jernih, hanya mampu memikirkan bagaimana caranya melampiaskan marah atau kesalnya, karena emosi sudah melumpuhkan kemampuan berpikirnya. Hal ini terlihat dari siswa sering melanggar aturan, datang terlambat, bolos, tidak mengerjakan tugas, prestasi belajarnya menurun, melawan guru, bahkan berkelahi dengan teman-temannya.

Layanan bimbingan kelompok adalah suatu kegiatan yang dilakukan oleh sekelompok orang dengan memanfaatkan dinamika kelompok. Artinya, semua peserta dalam kegiatan kelompok saling berinteraksi, bebas mengeluarkan pendapat, 
menanggapi, memberi saran, dan lain-lain sebagainya; apa yang dibicarakan itu semuanya bermanfaat untuk diri peserta yang bersangkutan sendiri dan untuk peserta lainnya (Prayitno, 1995: 178).

Tohirin (2007: 165) menjelaskan salah satu bentuk pelatihan yang diberikan kepada siswa untuk meningkatkan kemampuan mengelola emosi adalah dengan melalui layanan bimbingan kelompok, yaitu dengan cara memberikan kesempatan kepada siswa untuk mau mengemukakan pendapatnya didepan orang lain, belajar untuk bersabar dan menahan diri untuk tidak memotong pembicaraan pada saat yang lain sedang mengemukakan pendapat, belajar untuk menghargai dan menghormati pendapat orang lain, serta dapat memahami dan belajar untuk berempati pada saat kegiatan bimbingan kelompok sedang berlangsung.

Kasus seperti perkelahian dan perilaku agresif di SMAN 8 secara umum sering terjadi, siswa menunjukkan sikap agresif akibat emosi marah yang dirasakan, seperti berteriak-teriak ketika berbicara, mengumpat dan melotot ketika tersinggung dan saling memojokkan, memberi nama panggilan negatif, dan ketika siswa bercanda bersama bisa berubah menjadi pertengkaran. Begitu pula dalam mengatasi perasaan emosinya, siswa mengekspresikannya dengan cara membolos, membuat keributan dikelas, berbicara tidak sopan dengan guru, dan berbicara kasar dengan teman.

Hasil wawancara dengan guru BK disekolah juga menunjukkan bahwa masih banyak siswa yang belum dapat mengelola emosi dengan baik. Sebagian besar siswa masih kebingungan dan bersifat kekanak-kanakan seperti egois, tidak sabar, dan tidak berpikir panjang sebelum melakukan sesuatu. Siswa juga masih kurang mampu menyelesaikan masalahnya sendiri, cenderung menyimpan masalahnya sendiri dan kurang peka dengan apa yang dialami orang lain.

Keadaan seperti kasus di atas merupakan salah satu indikasi ketidaksiapan remaja menyikapi kondisi lingkungan sekitarnya. Rasa kecewa, malu, marah, dan perasaan-perasaan negatif lainnya yang bersumber dari ketidakmampuan remaja mengenali dan mengelola emosi serta memotivasi diri. Remaja belum mampu 
melakukan kontrol emosi secara tepat dan mengekspresikannya dengan cara yang tepat pula. Untuk itu perlu diupayakan agar siswa dapat meningkatkan kemampuan mengelola emosi yaitu melalui bimbingan kelompok.

Berdasarkan latar belakang tersebut, dapat dirumuskan permasalahan dalam penelitian ini adalah sebagai berikut :

1. Bagaimana kemampuan mengelola emosi siswa di SMA N 8 Kota Bengkulu sebelum diberikan layanan bimbingan kelompok?

2. Bagaimana kemampuan mengelola emosi siswa di SMA N 8 Kota Bengkulu setelah diberikan layanan bimbingan kelompok?

3. Bagaimana pengaruh layanan bimbingan kelompok terhadap peningkatan kemampuan mengelola emosi siswa SMA N 8 Kota Bengkulu?

\section{Metode Penelitian}

Metode penelitian yang digunakan dalam penelitian ini adalah eksperimen. Menurut Suryana (2010: 2), penelitian eksperimen adalah metode penelitian yang digunakan untuk mencari pengaruh perlakuan tertentu terhadap yang lain dalam kondisi yang dikendalikan. Desain yang digunakan pada penelitian ini adalah one group pre-test and post-test design. Dalam desain ini subjek dikenakan perlakuan 2 kali pengukuran.

Menurut Sugiyono (2014: 61), populasi adalah wilayah yang terdiri atas objek atau subjek yang mempunyai kualitas atau karakteristik tertentu yang diterapkan oleh peneliti untuk dipelajari dan kemudian diambil kesimpulan. Populasi dalam penelitian ini adalah siswa kelas XI SMAN 8 Kota Bengkulu, yaitu kelas XI IPA.

Menurut Sugiyono (2014: 62), sampel adalah bagian dari jumlah dan karakteristik yang dimiliki oleh populasi tersebut. Teknik pengambilan sampel dalam penelitian ini dengan menggunakan purposive sampling.Purposive samplingadalah teknik yang digunakan untuk penentuan sampel dengan pertimbangan tertentu.Peneliti memilih 10 orang yang akan dibentuk dalam satu kelompok untuk melaksanakan layanan bimbingan kelompok. Kelas XI IPA 1 dijadikan sampel 
penelitian karena memenuhi karakteristik subjek penelitian yang memiliki kemampuan mengelola emosi rendah.

\section{Hasil dan Pembahasan}

Dalam menentukan kategori perolehan skor subjek penelitian, diawali dengan mencari mean dan standar deviasi, dengan menggunakan Statistical Packages for Social Science (SPSS) for Window Release 16.

\begin{tabular}{lccc}
\hline Kategori & Interval & Frekuensi & $\%$ \\
\hline Sangat tinggi & $\geq 130$ & - & - \\
Tinggi & $123-129$ & - & - \\
Sedang & $118-122$ & - & - \\
Rendah & $107-117$ & 9 & $90 \%$ \\
Sangat rendah & $\leq 106$ & 1 & $10 \%$ \\
\hline
\end{tabular}

Hasil pengambilan data awal (pre-test) dikategorikan 9 orang siswa memiliki kemampuan mengelola emosi rendah dan 1 siswa yang memiliki kemampuan mengelola emosi sangat rendah. Sampel yang termasuk dalam kategori rendah akan diberikan layanan bimbingan kelompok. Pada hasil pre-testdapat disimpulkan bahwa siswa yang memiliki kemampuan mengelola emosi rendah kategori skor antara 107117 berjumlah 9 siswa dan kategori skor < 106 berjumalah 1 siswa. 10 siswa tersebut diberi layanan bimbingan kelompok sebanyak 5 kali.

Setelah diberikan layanan bimbingan kelompok, skala sikap tentang kemampuan mengelola emosi yang sebelumnya digunakan dalam pre-testdigunakan kembali dalam post-test. Diadakan post-testbertujuan untuk mengukur kemampuan mengelola emosi siswa setelah mendapatkan layanan bimbingan kelompok.

\begin{tabular}{lccc}
\hline Kategori & Interval & Frekuensi & $\%$ \\
\hline Sangat tinggi & $\geq 130$ & 4 & $40 \%$ \\
Tinggi & $123-129$ & 6 & $60 \%$ \\
Sedang & $118-122$ & - & \\
Rendah & $107-117$ & - & \\
Sangat rendah & $\leq 106$ & - & \\
\hline
\end{tabular}


Menggambarkan adanya peningkatan kemampuan mengelola emosi siswa yang semula berada di kategori rendah, dan sangat rendah. 4 siswa berada dikategori sangat tinggi, presentase sebesar 40\% dengan interval (>130). 6 siswa dikategori tinggi dengan presentase sebesar 60\% dengan interval (123-129).

Uji hipotesis ini menggunakan rumus Uji-Z, rumus ini digunakan untuk mencari pengaruh bimbingan kelompok dalam meningkatkan kemampuan mengelola emosi siswa. Untuk menguji hipotesis digunakan uji non parametrik dengan rumus Wilcoxon Signed Rank dengan menggunakan SPSS. Menggunakan uji Wilcoxon Signed Rank Test untuk melihat apakah ada pengaruh layanan bimbingan kelompok dalam meningkatkan kemampuan mengelola emosi siswa kelas XI SMAN 8 Kota Bengkulu. Kriteria pengujian hipotesis menggunakan uji $\mathrm{Z}$ adalah jika nilai sig (2 tailed $)>0.05$ maka hipotesis $\left(\mathrm{H}_{0}\right)$ diterima dan $\left(\mathrm{H}_{\mathrm{a}}\right)$ ditolak, sebaliknya jika nilai sig (2 tailed $)<0.05$ maka hipotesis $\left(\mathrm{H}_{0}\right)$ ditolak dan $\left(\mathrm{H}_{\mathrm{a}}\right)$ diterima. Hipotesis yang tersusun dalam penelitian ini adalah sebagai berikut :

a. $\mathrm{H}_{0}$ : Tidak ada pengaruh bimbingan kelompok dalam meningkatkan kemampuan mengelola emosi siswa.

b. $\mathrm{H}_{\mathrm{a}}$ :Ada pengaruh bimbingan kelompok dalam meningkatkan kemampuan mengelola emosi siswa.

Hasil uji Z (-2.879) dan menunjukkan bahwa nilai Sig. (2 tailed)sebesar 0,004 yang artinya nilai Sig. (2 tailed)<0,05 maka hipotesis (H0) ditolak dan (Ha) diterima, maka dapat disimpulkan bahwa ada pengaruh layanan bimbingan kelompok dalam meningkatkan kemampuan mengelola emosi siswa kelas XI SMA Negeri 8 Kota Bengkulu.

\section{Hasil dan Pembahasan}

Penelitian dilakukan dari tanggal 26 Maret 2018 sampai dengan tanggal 5 Mei 2018. Pada tanggal 26 Maret 2018 dilakukan pre-test kepada siswa kelas XI IPA 1.Diketahui setelah diberikan angket kemampuan mengelola emosi terdapat 10 orangsiswa (AAP, RIF, RPB, RAP, YH, STA, CTA, MN, TY,TA) dalam kategori 
rendah dan sangat rendah. Berdasarkan hasil pre-testyang telah dilakukan dengan skor rata-rata menunjukkan kemampuan mengelola emosi yang rendah membutuhkan perlakuan dan terwjudnya dinamika kelompok dalam kegiatan bimbingan kelompok agar kemampuan mengelola emosi dapat meningkat. Menurut Sunarto \& Hartono (2013: 156) rendahnya kemampuan mengelola emosi siswa disebabkan oleh beberapa faktorinternal dan eksternal, yaitu faktor internal menyangkut pengendalian diri siswa, pola pandang serta kebiasaan-kebiasaan yang ditumbuhkannya dalam merespon suatu permasalahan. Faktor eksternal antara lain adalah situasi-situasi di luar diri seseorang yang memancing respon emosional, latar belakang keluarga, serta budaya dan lingkungan sekitar.

Berdasarkan hasil uji hipotesis yang telah diberikan, diperoleh hasil bahwa terdapat pengaruh yang signifikan antara layanan bimbingan kelompok terhadap kemampuan mengelola emosi yang memperoleh perlakuan bimbingan kelompok dengan nilai yang signifikan 0,004 yang berarti $0,004<0,05$ dengan nilai $\mathrm{Z}=-2.879$. Jadi dapat diketahui bahwa H0 ditolah dan Ha diterima, yang berarti ada pengaruh layanan bimbingan kelompok dalam meningkatkan kemampuan mengelola emosi siswa yang memperoleh perlakuan bimbingan kelompok yaitu AAP, RIF, RPB, RAP, YH, STA, CTA, MN, TY,TA.

Hasil yang diperoleh dalam penelitian ini relevan dengan penelitian yang dilakukan oleh Betsaidah Riaty (2015) yang berjudul Penerapan Layanan Bimbingan Kelompok Teknik Role Playing dalam Meningkatkan Kemampuan Mengelola Emosi Siswa Kelas XII IPS 3 di SMAN 12 Medan. Dalam penelitian ini dapat disimpulkan bahwa ada pengaruh layanan bimbingan kelompok terhadap kemampuan mengelola emosi siswa. Hal ini dapat diketahui dari meningkatnya kemampuan mengelola emosi setelah diberikan bimbingan kelompok.

Selanjutnya hasil penelitian ini sesuai dengan hasil penelitian Selly Marselina (2017) yang berjudul Analisis Layanan Bimbingan Kelompok tentang Perkembangan Emosi Remaja Kelas X SMA Santun Untan Pontianak. Pada hasil penelitian Selly 
Marselina dikatakan bahwa perkembangan emosi dapat ditingkatkan dengan menggunakan bimbingan kelompok.

Berdasarkan hasil penelitian, kajian teori, dan penelitian yang relevan maka dapat disimpulkan bahwa layanan bimbingan kelompok berpengaruh dalam meningkatkan kemampuan mengelola emosi siswa SMA Negeri 8 Kota Bengkulu.

\section{Kesimpulan}

Berdasarkan hasil dari penelitian pada kelas XI SMA Negeri 8 Kota Bengkulu, analisis data dan uji hipotesis yang telah dilakukan maka dapat disimpulkan bahwa:

1. Kemampuan mengelola emosi siswa sebelum diberikan layanan bimbingan kelompok masih tergolong rendah, ini terlihat dari rata-rata pre testyaitu dalam kategori rendah.

2. Kemampuan mengelola emosi siswa setelah diberikan layanan bimbingan kelompok meningkat, ini terlihat dari rata-rata skor post test yaitu pada kategori tinggi.

3. Terdapat pengaruh layanan bimbingan kelompok dalam meningkatkan kemampuan mengelola emosi siswa kelas XI di SMAN 8 Kota Bengkulu, terlihat dari hasil uji $\mathrm{Z}=-2.879$ dan Sig. (2-tailed)sebesar 0,004 yang artinya nilai $\mathrm{p}<$ 0,05 maka hipotesis $\left(\mathrm{H}_{0}\right)$ ditolak dan $\left(\mathrm{H}_{\mathrm{a}}\right)$ diterima.

\section{Daftar Pustaka}

Ali, M \& Ansori, M. (2004). Psikologi Remaja Perkembangan Peserta didik. Jakarta: Bumi Aksara.

Goleman, D. (1995). Emotional Intelligence. Jakarta: Gramedia Pustaka Utama.

Hurlock, E. B. (1980). Perkembangan Anak. Jakarta: Erlangga.

Marselina, S.(2017). Analisis Layanan Bimbingan Kelompok Tentang Perkembangan Emosi Remaja. Jurnal Pendidikan dan Pembelajaran, 6(10), 1-12. 
ISSN 2599-1221 (Cetak)

ISSN 2620-5343 (Online)

https://ejournal.unib.ac.id/index.php/j_consilia

Prayitno, (1995). Buku Seri Bimbingan dan Konseling di Sekolah Layanan Bimbingan dan Konseling Kelompok. Padang: Ghalia Indonesia

Riaty, B. (2015). Penerapan Layanan Bimbingan Kelompok Teknik Role Playing Dalam Meningkatkan Kemampuan Mengelola Emosi Siswa.JurnalProgram Studi PGSD FIP Unimed, 3(1), 129-137.

Sugiyono. (2016). Metode Penelitian Kuantitatif Kualitatif dan $R \& D$. Bandung: Alfabeta.

Sugiyono. (2014). Statistika untuk Penelitian. Bandung: Alfabeta.

Sunarto, \& Agung H. (2013). Perkembangan Peserta didik. Jakarta: Rineka Cipta.

Suryana. (2003). Pedoman Praktis. Jakarta: Selemba Empat.

Tohirin, (2007). Bimbingan dan Konseling di Sekolah dan Madrasah Berbasis Integrasi. Jakarta: Raja Grafindo Persada. 